\title{
Para leer a Teilhard de Chardin *
}

\section{La dialéctica teilhardiana}

Leer a Teilhard de Chardin es una aventura intelectual. $Y$ es una verdadera aventura porque - a pesar de sus audacias de léxico- Teilhard es un autor aparentemente fácil, pero que, en realidad, se mueve entre supuestos implícitos, epistemológicos y metódicos, que es preciso tener en cuenta a la hora de leerle, para entender y penetrar adecuadamente su pensamiento. Gran parte de la polémica apasionada en torno suyo se debe a malentendidos. $Y$ esto vale tanto para los admiradores entusiastas como para los detractores sistemáticos.

De hecho, el adversario y el discípulo lúcido son raros. $Y$ es que ambos llegan a él desde una situación intelectual muy diferente, entre sí y respecto a Teilhard. Por eso, ambos pueden quedar igualmente distantes ide la realidad. Con frecuencia se ha divulgado un teilthardismo de pacotilla. Creo que el verdadero debate en torno al sabio jesuíta comenzará ahora, cuando las pasiones se van calmando y se empieza a estudiar seriamente su obra. Ya ha pasado el momento de los coloquios y de las mesas redondas. Se precisa una circunscripción del pensamiento teilhardiano en sus límites y dimensiones reales, evitando la precipitación tanto como la prevención.

Los malentendidos parten, casi siempre, de una actitud inicial equivocada. No se puede leer a un autor tan original y complejo bajo la perspectiva escolástica, hegeliana o marxista. La correspondencia Blondel-Teilhard, comentada magistralmente por De Lubac, ha mostrado también lo limitado de la influencia blondeliana. Bergson cumplió más bien una función catalizadora de su pensamiento, pero ambos se mueven en universos muy diferentes. Hegel nunca fue estudiado a fondo por el sabio jesuíta y si está demostrado que el marxismo en-

* Hemos de agradecer a Ediciones Taurus su esfuerzo editorial para poner en manos del público español las obras de Teilhard de Chardin. Las versiones son, en general, muy aceptables y llevan una introducción aclaratoria. La presentación es modesta, pero digna. Hasta el presente han aparecido las siguientes obras: Cartas de viaje. El grupo zoológico humano. La aparición del hombre. La visión del pasado. El medio divino. Nuevas cartas de viaje. El porvenir del hombre. El fenómeno humano. La energía humana. Génesis de un pensamiento. La activación de la energía. Escritos del tiempo de la guerra. Cartas de Egipto. Himno del universo. 
traba en sus preocupaciones fundamentales, se trata primordialmente de un afrontamiento superador, que aparece, además, en la segunda época de su vida.

En efecto, no se puede leer a Teilhard con la mentalidad estática y puramente analítica que domina todavía en la filosofía tradicional. La inducción-deducción escolásticas ignoran la fecundidad de los contrarios. Tras Darwin y Hegel, la posición exclusivamente analítica se ha mostrado insuficiente. Las oposiciones se alinean según la figura de una alternativa: persona o socialización, libertad o necesidad, naturaleza o conciencia, sociología o historia... Porque tampoco la analogía basta. La dialéctica ha demostrado que lo opuesto, lo diverso, lo pluralístico, significan solamente momentos de un movimiento superador, elementos complementarios que se unen armónicamente en una síntesis superior. El razonamiento lineal se ha mostrado igualmente insuficiente. La realidad — siempre única, pero siempre compleja - sólo puede alcanzarse a través de confrontaciones, antítesis y mediaciones. Es la totalidad operante, coherente a la vez que superadora de sí misma. La dialéctica es ya un presupuesto básico de conocimiento. En todo caso, el universo teillhardiano es un universo dialéctico.

Por otra parte, tampoco debe olvidarse que Teilhard no es un filósofo de escuela, sino un intuitivo muy lúcido. Más que un sistema es un método, "un haz armonioso de vectores ordenados hacia el porvenir... un haz de ejes de progresión tal cual existen... en todo sistema de evolución". Pero es un método nuevo, totalmente original. Sólo hay esbozos de una teoría del conocimiento: un realismo orítico. Su intuición central la ha definido Cuénot como "diafanidad crística de la materia", en sus múltifles facetas. Unitas multiplex, una unidad creadora que asimila y sobrepasa lo múltiple sin aniquilarlo. Un proceso continuo en dos movimientos complementarios: divengente, movimiento de excentración; y convergente, de concentración y constante superación (ultra, supler, bypier). Tampoco debe olvidarse que Teilhard de Chardin utiliza con frecuencia la extrapolación científica, no sólo en extensión (al pasado o al futuro), sino también en profundidad. Pero la categoría fundamental de su pensamiento es la dialéctica evolutiva. Esta mentalidad es igualmente imprescindible en el lector para comprenderle adecuadamente.

La perspectiva dialéctica es suficiente para aclarar la mayor parte de las dificultades y hace posible una penetración más profunda del pensamiento teilhardiano. A mi entender, el sentido dialéctico es la clave iluminadora de toda su problemática. En primer lugar, de la discutida fenomenología integral. Igualmente para comprender todo el alcance de su terminología. Hoy contamos ya con un notable Léxico TCh debido a Cuénot y otros cuatro colaboradores. Su indudable valor queda reducido por la ausencia parcial de la interpretación dialéctica. También para explicar el sentido de su intento sistematizador siempre "provisional". Y, finalmente, para ilustrar la necesidad de leerle por orden cronológico, 
que es también el genético. Tal es el programa que vory a intentar precisar brevemente a continuación.

Ante todo una aclaración: la dialéctica nada resuelve si la entendemos de acuerdo con otro "modelo", sea platónico, hegeliano o marxista. En Teilhard tiene un sentido propio, original, aunque sumamente complejo. Por temperamento fue refractario siempre a todo influjo. Puede afirmarse incluso que el pensamiento ajeno no le interesaba apenas. Pero su expresión es sutil, plena de matices. Por eso será mejor que distinga desde el principio dos sentidos netamente diferenciados de su dialéctica: un sentido topolóigico, como segunda etapa del universo teilhardiano; y un sentido lógico, como forma de pensamiento.

El primer sentido es muy claro y ha sido expuesto muy precisamente por Cuénot, valiéndose del esquema del mismo Teilhard (en su diario y en carta a Monseñor Solages) :

\section{Diario, 27 agosto 1947 \\ "Mi universo"}

1. FISICA (consecuencia de dos descubrimientos: Duración orgánica del Tiempo-Espacio Grandes números), ley de complejidadconciencia.

2. DIALECTICA: Punto Omega, Revelación, Cristo Omega...

3. METAFISICA: La unificación de lo múltiple. Creación-EncarnaciónRedención (Mal)-Pléroma...

4. MISTICA: La Mística del Oeste. El golden glow (diafanía crística de la materia).
Carta a Mons. Solages, 2 set. 1947

"Plan de trabajo"

Una FISICA (Fenómeno humano).

Una DIALECTICA (paso del fenómeno humano al Punto Omega. Emersión fuera del círculo fenomenal, y Revelación).

Una METAFISICA (Metafísica de la Unión. Creación unitiva = Encarnación $=$ Redención, Mal).

Una MISTICA (Caridad evolutiva, Cristo humanizador, Mística del Oeste).

Sin embargo, tal vez fuera preferible adoptar el esquema que propuso el mismo Teilhard dos años después en un artículo publicado en 1949. El esquema queda reducido a una Física, una Apologética y una Mística. Las dos etapas intermedias se han fundido, pues, en la Apologética, cuyo sentido dialéctico esbozaré más adelante.

El sentido lógico es el que más me interesa destacar aquí. Pero se trata también de un concepto complejo que es preciso matizar cuidadosamente. En primer lugar asistimos a una progresiva toma de conciencia dialéctica en el mismo 
Teilhard. Sus líneas generales aparecen por primera vez en el opúsculo apologético Comment je crois (1934). En Le Pbênomiène buamain (1938-1940) es ya un intento sistemático de aplicación. M. Barthélemy-Madaule ha sido la primera en precisar que la concepción dialéctica va creciendo en Teilhard conforme los problemas thistóricos y sociales van dominando su preocufación intelectual. Esta toma de conciencia explícita debió tener lugar poco después de 1940. Dos obritas llevan ya el título expreso: La Centrologie, essai d'une dialectique de l'union (1944) y Esquisse d'une dialectique de l'esprit (1946). Hemos de distinguir, pues, diversas retapas en su concepción dialéctica, que deberán ser tenidas en cuenta a la hora de la lectura y de la interpretación, también con sentido y valor genético.

Primera etapa: Dialéctica implicita, pensamiento existencialmente dialéctico. La conrespondencia recogida en Genèse d'une pensée y los primeros escritos de Teilhard de Chardin revelan una profunda vivencia de la oposición -que en su interior se traduce en lucha patética- entre el "sentido cósmico" y el "sentido crístico", el "hijo de la tierra" y el "hijo del cielo", que busca afanosamente la armonía entre ambas corrientes: el "Hacia adelante" y el "Hacia arriba". Sus primeros intentos de "vía media" fracasaron. Pero muy pronto intuye la solución en la dialéctica evolutiva, que progresivamente se impone a su espíritu sobre la mentalidad analítico-analógica de su formación. Con el descubrimiento de lo dialéctico su espíritu se embarca definitivamente por la vía sintética y unificadora, bajo la difusa y catalizadora influencia bergsoniana: "transformación creadora". Pero es una dialéctica implícita e imprecisa, que denomino genéricamente dialéctica evolutiva. Se trata más bien de un pensamiento existencialmente dialéctico.

Segunda etapa: Progresiva toma de conciencia dialéctica. El opúsculo Comment je crois (1934), de naturaleza primordialmente apologética, formula ya los primeros avances de su mentalidad dialéctica. En efecto, Teilhard declara equivocados los intentos concordistas y "mediocres" (vía media). Treinta años de lucha y de tanteos le han llevado a ver claramente: la solución está en la síntesis, la unificación en un plano superior. En 1946 ("Esquisse") el sabio jesuíta invitará a una lectura dialéctica de esta obrita, declarando equivalentes ambos conceptos: "Mon apologétique au si l'on préfère ma dialectique". Y es que no hay movimiento dialéctico sin un sentido y ello sufone, implícita o explícitamente, una totalidad virtual. Nos movemos en un "champ d'attraction finalisé".

Sería equívoco afirmar con Cuénot que Le Phénomène bumain es una dialéctica de la naturaleza. En todo caso habría de entenderse como una etapa de la dialéctica del espíritu. El prólogo de la obra es muy expresivo a este respecto, delineando una teoría del conocimiento en la que el hombre es "inevitablemente, centro de persepectiva y centro de construcción", según una auténtica estructura de interioridad. En el fondo todo significa una síntesis de sujeto y objeto en re- 
lación unificante-dialéctica. Una fenomenología integral rehusa la dualidad de un orden cognoscitivo y un orden real.

Alguna vez se ha confundido con los bergsonianos "análisis sucesivos". En Teilhard asistimos a una "sed de síntesis y de convergencia", si bien no se excluye el análisis, sino que se supone previamente. "Ver" es sintetizar provisionalmente, en desvelación progresiva del movimiento inherente a la síntesis. El desarrollo concreto de Le Phénomiène bumiain es la historia de una creación evolutiva, en la que un tout nowveau emerge por maduración (transformación) de lo antiguo. El no tener en cuenta la naturaleza dialéctica de la obra ha dado lugar a numerosos malentendidos. La relación biológico-social, por ejemplo. Igualmente la relación fenomenología-ontología. Precisamente, lo ontológico es lo que se va desvelando más y más a través de lo fenomenológico. También el concepto de analogía. Teilhard habla siempre de una analogía dinámica, no estática, que —en último término- viene a coincidir con la creación evolutiva: "todo se hace por transformación de una analogía preexistente". Es decir, se trata de una analogía genética y dialéctica.

El "salto", la nueva síntesis (seuil, point critique, pas) marca la conjunción de continuidad y discontinuidad, la emengencia die un todo nuevo. Esto resulta inexplicable sin una dialéctica evolutiva. Tenemos, adiemás, la clara aserción del mismo Teilhard: "La evolución... es una condición general die nuestro conocimiento... es una luz que ilumina todos los hechos, una dirección que todas las líneas deben seguir". Precisamente, a partir de los "umbrales críticos" (vida, célula, hombre) va a establecer su famosa ley recurrente de complejidad-conciencia, que le va a permitir alcanzar la previda, lo precéntrico y lo prehumano.

Pero esta creación evolutiva no ha de entenderse como una simple marcha hacia lo complejo, sino como una inmensa metamorfosis de la que resulta también una inmensa analogía. De este modo se hace posible que "los espiritualistas tengan razón cuando reclaman la trascendencia del hombre e, igualmente, los materialistas cuando postulan su inmanencia terrestre: por discontinuidad de continuidad". La unión transformadora asume las oposiciones y las sobrepasa realmente. En el ámbito de la Noosfera la dialéctica se convertirá en amor, "motor del universo", que permitirá la fusión armónica de individualidad y sociedad en la síntesis superior de lo personal. $\mathrm{El}$ predominio de categorías biológicas -que si le ha reprochado- se explica fácilmente for el hecho de que en todo pensador encontramos el mismo fenómeno: predomina la estructura de su especialidad preferida. No puede concluirse, pues, un biologismo.

Tercera etapa: Dialéctica explicitada. En 1946 formula Teillhand ya claramente el sentido preciso de su dialéctica en el opúsculo Esquisse d'une dialectique de l'esprit, que había sido ya aplicadia en el orden fenoménico-ontológico en 
La Centrologie, essai d'une dialectique de l'union (1944), o dialéctica del universo (incluídos ambos en el tomo "La activacióni de la energía").

En la Esquisse la dialéctica nos es presentada bajo unas categorías epistemológicas, en la misma línea del famoso prólogo de Le Phénomène bumain, es decir, bajo las estructuras dinámico-sintéticas del "ver". No es mi intención hacer un análisis detallado de la dialéctica teilhardiana. Me propongo simplemente orientar a los lectores de Teilhard sobre este concepto fundamental de su método. Expresado en una fórmula concisa, "ver" es construir por sucesivas mediaciones sujeto-objeto. En último término tenemos una dialéctica de la unión, de la síntesis transformadora. La búsqueda es incesante. Las síntesis son cada vez más compren. sivas, pero siempre "provisionales". Cada ascensión es un esfuerzo laborioso de clarificación y de penetración del tout unique. Teilhard llega a hablar incluso de "iluminación sintética".

La Centrologie lleva el expresivo subtítulo de "dialéctica de la unión". Es un intento formidable de sistematización en el que Chardin se propone precisar su posición y deshacer equívocos. Es un libro que debiera leerse a continuación de Le Phénomène. La sistematización sigue el programa - ya expuesto- en cuatro tiempos: Física (fenómeno humano, complejidad-conciencia), Dialéctica (paso del fenómeno humano al Punto Omega), Metafísica (creación unitiva-Encarnación-Redención) y Mística (Cristo humanizador). La dialéctica del universo queda expuesta en una síntesis decantadora de conceptos y de lexicología.

CoNCLusión.--La dialéctica teilhardiana es, pues, una dialéctica del espíritu. No aparece en el cosmos más que a partir del acto del sujeto. Todo sentido marxista queda excluído. El sujeto percibe en lo real el mismo proceso de unión que existe en sí mismo y, de esta manera, discierne el acto unitivo del Es.píritu -a la vez universal y personal- que es Dios creador. No puede hablarse, pues, de una dialéctica de la naturaleza más que como una etapa en la toma de conciencia del primado del Espíritu. Estamos en una dialéctica simultánea del ser y del conocer. Por lo que tampoco nos movemos en un idealismo, porque la naturaleza no puede treducirse a una construcción del espíritu. En otros términos, es un movimiento totalizante, típicamente teilhardiano, que se desarrolla en dos momentos sintéticos y complementarios: umbrales de discontinuidad o etapas de creación evolutiva y proceso de convergencia, en el que el universo entero se dirige a un punto de encuentro: el Punto Omega.

P. José RubIo 